\title{
OXIDIZED LOW-DENSITY LIPOPROTEIN AND ANKLE-BRACHIAL PRESSURE INDEX IN PATIENTS WITH CLINICALLY EVIDENT PERIPHERAL ARTERIAL DISEASE
}

\author{
Ruben Miguel Ayzin Rosoky, ${ }^{\mathrm{I}}$ Nelson Wolosker, ${ }^{\mathrm{I}}$ Michel Nasser, ${ }^{\mathrm{I}}$ Antonio Eduardo Zerati, ${ }^{\mathrm{I}}$ Magnus Gidlund, ${ }^{\mathrm{II}}$ Pedro Puech- \\ Leão ${ }^{\mathrm{I}}$
}

doi: $10.1590 /$ S1807-59322010000400006

Rosoky RMA, Wolosker N, Nasser M, Zerati AE, Gidlund M, Puech-Leão P. Oxidized low-density lipoprotein and anklebrachial pressure index in patients with clinically evident peripheral arterial disease.Clinics. 2010;65(4):383-7.

OBJECTIVES: To investigate whether oxidized low-density lipoprotein is a suitable predictor of peripheral arterial disease severity. The role of oxidized low-density lipoprotein in the pathogenesis of atherosclerosis has already been investigated. Its relevance as a predictor of the appearance and worsening of coronary arterial disease is also well known. However, the same is not true regarding peripheral arterial disease.

METHOD: Eighty-five consecutive patients with an ankle-brachial pressure index (ABPI) $<0.9$ and the presence of either intermittent claudication or critical lower leg ischemia were included. The plasma level of IgG autoantibodies against oxidized low-density lipoprotein was evaluated through an enzyme-linked immunosorbent assay. The results were categorized into quartiles according to the ankle-brachial pressure index (a marker of peripheral arterial disease severity), and significant differences were investigated with the Kruskal-Wallis test.

RESULTS: There was no significant difference between the quartiles for this population $(\mathrm{p}=0.33)$. No correlation was found between the ankle-brachial pressure index and oxidized low-density lipoprotein levels in subjects with clinically evident peripheral arterial disease with a wide range of clinical manifestations.

CONCLUSIONS: Oxidized low-density lipoprotein is not a good predictor of peripheral arterial disease severity.

KEYWORDS: Atherosclerosis; Cholesterol; Free radical; Limb ischemia; Predictor.

\section{INTRODUCTION}

The importance of laboratory predictors of the severity of common diseases has been growing along with the increasing availability of early therapeutic approaches to prevent or minimize disease-related complications. Therefore, the incidence and severity of atherothrombotic complications could be significantly reduced if the patients at higher risk for these complications are properly

Work performed at the Hospital das Clínicas, Faculdade de Medicina da Universidade de São Paulo - São Paulo/SP, Brazil.

${ }^{\mathrm{I}}$ Department of Vascular and Endovascular Surgery, Hospital das Clínicas, Faculdade de Medicina da Universidade de São Paulo - São Paulo/SP, Brazil.

II Department of Immunology, Hospital das Clínicas, Faculdade de Medicina

da Universidade de São Paulo - São Paulo/SP, Brazil.

Tel.: 55113071.1464

Email: aezerati@uol.com.br

Received for publication on November 30, 2009

First review completed on: January 19, 2010

Accepted for publication on January 19, 2010 anticipated. However, one of the foremost current challenges is identifying patients with a higher risk of a poor outcome before the appearance of complications. Having these patients identified would cause a major impact not only on the quality of life of individual subjects but also on the pharmacoeconomy of entire communities, since the allocation of resources would be more rational.

Many laboratory markers have been investigated to determine if they are predictive of an increased risk of atherosclerosis progression and the emergence of its complications. With regard to peripheral arterial disease (PAD), thrombomodulin blood levels, for example, were not significantly elevated in patients with critical limb ischemia in comparison to patients with intermittent claudication. Thus, thrombomodulin is not a good predictor of PAD worsening. ${ }^{1}$

Among the clinical and laboratory markers available, the ankle-brachial pressure index (ABPI) is a well-known 
predictor of PAD worsening. ${ }^{2}$ A low ABPI was associated with an increased risk of cardiovascular events, including death, independent of metabolic syndrome and other major cardiovascular disease risk factors. ${ }^{3}$ Furthermore, Fowkes et al. recently demonstrated that ABPI determination may improve the accuracy of cardiovascular risk prediction beyond the one achieved when using the Framingham risk score. ${ }^{4}$

The value of oxidized low-density lipoprotein (oxLDL) as a predictor of atherothrombotic complications has also been investigated. OxLDL was associated with carotid intimal-media thickness, unstable plaques in the coronary and carotid arteries, impaired brachial and coronary endothelial function, and coronary artery disease.

Moreover, oxLDL was also associated with the presence, extent,and interim development of carotid and femoral atherosclerosis over a five-year period.

However, only limited data are available regarding a potential relationship between ABPI and plasma oxLDL levels in subjects with PAD.

Because ABPI is primarily a severity index of the peripheral arteries' disease, we hypothesized that patients with lower ABPI would have higher plasma oxLDL levels than patients with higher ABPI.

The aim of the present study was to investigate such a correlation in patients with PAD.

\section{METHODS}

\section{Population}

Eighty-five consecutive patients with PAD from the Vascular Surgery Division of the Hospital das Clinicas of the University of São Paulo were included in this study. The inclusion criteria were an ABPI $<0.90$ and the presence of either intermittent claudication or critical lower leg ischemia. Informed consent from all subjects was obtained before this trial.

\section{Autoantibody plasma level evaluation}

A blood sample was drawn from a vein in the arm of each subject after an eight-hour overnight fast. The plasma was isolated and stored for subsequent analysis after centrifugation at $2500 \mathrm{rpm}$ and $4{ }^{\circ} \mathrm{C}$ for 20 minutes.

The plasma level of IgG autoantibodies against oxLDL (from this point on mentioned just as oxLDL levels) was evaluated as previously described. ${ }^{5}$ In brief, an enzymelinked immunosorbent assay was used. The optical density of the samples was read in a photometric plate reader at 460 $\mathrm{nm}$. Each plate was calibrated against an internal control (total $\mathrm{IgG}$ with protein concentration of $0.116 \mu \mathrm{g} / \mathrm{mL}$ in phosphate-buffered saline [PBS]; $\mathrm{pH} 7.4 ; 0.05 \mathrm{M}$ ) and a blank PBS sample. Thus, the results for oxLDL levels are shown according to the following formula: (anti-oxLDL antibody - blank)/internal control.

\section{Statistical analysis}

The oxLDL levels were categorized into quartiles according to ABPI, and the Kruskal-Wallis test was used to investigate whether there was a significant difference among quartiles. The level of significance was set to 0.05 .

\section{RESULTS}

Table 1 shows the demographic data of the sample population from this study. It shows the predominance of smoking and hypertension as risk factors for PAD, and also the higher incidence of the disease in males. The ABPI's interquartile range is quite wide, depicting this sample is highly representative of the population of patients with PAD.

Table 2 depicts the median oxLDL levels per ABPI quartile. There seems to be no substantial variation in oxLDL levels among the different ABPI quartiles.

The statistical analysis revealed that there is no significant difference in oxLDL level among the ABPI-based quartiles for this population $(\mathrm{p}=0.33)$.

Table 1 - Demographic data of the sample population.

\begin{tabular}{lc}
\hline Mean age (years) & $65.31 \pm 10.44$ \\
Proportion of males & $65.88 \%$ \\
ABPI $^{*}$ (median $\pm \mathrm{IQR}^{\dagger}$ ) & $0.45 \pm 0.63$ \\
Duration of PAD (months) & $24.88 \pm 29.91$ \\
Proportion of smokers (any point in lifetime) & $74.12 \%$ \\
Proportion of diabetic patients & $37.65 \%$ \\
Proportion of hypertensive patients & $61.18 \%$ \\
OxLDL & (median $\pm \mathrm{IQR})$ \\
\hline
\end{tabular}

$*$ ankle-brachial pressure index; ${ }^{\dagger}$ interquartile range; ${ }^{\dagger}$ peripheral arterial disease; ${ }^{\S}$ oxidized low-density lipoprotein

Table 2 - Median oxLDL levels per ABPI quartile.

\begin{tabular}{lcccc}
\hline Quartile & $1^{\text {st }}$ & $2^{\text {nd }}$ & $3^{\text {rd }}$ & $4^{\text {th }}$ \\
\hline ABPI $^{*}$ median & 0 & 0.38 & 0.53 & 0.68 \\
OxLDL & 0.21 & 0.14 & 0.17 & 0.16 \\
\hline
\end{tabular}

${ }^{*}$ ankle-brachial pressure index; ${ }^{\dagger}$ oxidized low-density lipoprotein

\section{DISCUSSION}

Profiling patients for risk factors regarding peripheral arterial disease is a continuously ongoing process. ${ }^{6-10}$ 
Among the many studied markers of PAD worsening, oxLDL is earning increasing importance as evidence of its participation in atherogenesis has accumulated.

The development of atherosclerosis depends on a delicate balance between proinflammatory stimuli and antiinflammatory, anti-oxidative defense mechanisms.

A typical feature of atherosclerosis is the accumulation of oxidatively modified low-density lipoproteins within plaques, and these lipoproteins are hypothesized to contribute to the inflammatory state of atherosclerosis and to play a key role in its pathogenesis.

As low-density lipoproteins (LDL) traverses the subendothelial space, it becomes oxidized and may induce endothelial dysfunction, one of the earliest manifestations of atherosclerosis. Indeed, oxLDL levels correlate with the occurrence of endothelial dysfunction. Endothelial dysfunction improves following lipid-lowering therapy with apheresis or statins. ${ }^{11}$

Native, non-oxidized lipoproteins elicit no or only weak effects on the production of reactive oxygen species. On the other hand, oxidation of LDL increases its capacity to stimulate $\mathrm{O}_{2}^{-}$formation, either through activating the lectin-like receptor LOX-1 ${ }^{12}$ or increasing the production and concentration of asymmetric dimethyl L-arginine. ${ }^{13}$ The latter is an endogenous inhibitor of nitric oxide synthase and increases oxidative stress. ${ }^{14}$

OxLDL-induced $\mathrm{O}_{2}^{-}$accumulates at the site of inflammation within atherosclerotic plaques, in the direct vicinity of all cell types that are involved in the pathogenesis of the disease. Experimental data showed that this accumulation may lead to cell proliferation, hypertrophy, apoptosis, or necrosis, depending on the amount and duration of the exposure of the cells to oxLDL. ${ }^{15,16}$ Moreover, this accumulation may also inactivate nitric oxide ${ }^{17}$ and sensitize the contractile apparatus of the vessel wall, thus inducing vasoconstriction. ${ }^{18}$

OxLDL is not present in normal arteries. However, it is present in many types of lesions, including very early fetal aortic lesions that form in response to maternal hypercholesterolemia during gestation. OxLDL is present even before monocytes enter into the vessel wall, suggesting that LDL oxidation occurs $a$ priori in atherogenesis. ${ }^{19}$

Unstable plaques in human carotid and coronary arteries are significantly enriched for oxLDL. Carotid plaques that were removed with endarterectomy and considered vulnerable and unstable plaques after pathology studies presented a much greater content of oxLDL than stable carotid plaques. ${ }^{20}$ Furthermore, another study showed that such content was significantly decreased after treatment with statins. ${ }^{21}$ In addition, oxLDL plasma levels correlate with the incidence of angiographically complex coronary plaques. ${ }^{22}$
The role of oxLDL as a marker or predictor of atherosclerotic involvement or atherothrombotic complications has already been assessed through some interesting studies. These studies show correlations of oxLDL plasma levels with morphologic and functional abnormalities, as well as with clinical outcomes.

In subjects with familial hyperlipidemia, elevated blood oxLDL and LDL-cholesterol levels were associated with increased carotid intimal-media thickness. ${ }^{23}$ In two other studies, elevated plasma oxLDL levels were associated with increased carotid intimal- media thickness in asymptomatic subjects whose relatives had familial hypercholesterolemia and also in asymptomatic middle-aged males..$^{24,25}$

A strong correlation between endothelial function abnormalities and high plasma levels of oxLDL was also demonstrated with regard to the coronary and brachial arteries. ${ }^{26,27}$ OxLDL plasma levels were also independent predictors of coronary artery disease ${ }^{28}$ and were even stronger predictors than LDL and total cholesterol blood levels. ${ }^{29}$

Finally, a prospective case-control study in men showed that oxLDL plasma levels were higher in the patients who would later present cardiovascular events compared to those who sustained no such events in the future. ${ }^{30}$

Our results showed no correlation between the ABPI and oxLDL levels in subjects with clinically evident PAD with a wide range of clinical manifestations. This finding differs from the results of some other investigations.

A study involving apparently healthy, atherosclerosisfree individuals, with ages ranging from 35 to 55 years, found an association between high oxLDL blood levels and the presence of plaques, or at least intimal thickening, in the femoral arteries..$^{31}$ Another trial demonstrated that the oxidized phospholipids/apolipoprotein B ratio was strongly and significantly associated with the presence, extent and development of carotid and femoral atherosclerosis and predicted the presence of symptomatic cardiovascular disease. ${ }^{32}$ Taken together, these two studies show that elevated plasma oxLDL levels may either appear before the disease becomes clinically evident or be strong predictors of the worsening of the disease in the future.

Another key aspect when assessing the relevance oxLDL levels as a severity predictor is its timing.

In this way, it was already observed that long-standing type 2 diabetic patients show a significant inverse correlation between the ABPI and plasma oxLDL levels; this correlation is not observed in recently diagnosed type 2 diabetic subjects. ${ }^{33}$

It is important to stress that the long-standing diabetic group mentioned above presented an ABPI of $0.86 \pm 0.29$ (mean \pm standard deviation), which is significantly higher 
than the ABPI found in our population. The finding of a higher ABPI is a sign that some individuals of that group had no or very early atherosclerotic compromise, in sharp contrast with a substantial lower median ABPI found in our population.

In our study, all the patients were in an advanced stage of PAD. Nonetheless, a wide range of clinical severities was observed within that population. Therefore, plasma oxLDL levels were assessed in patients with diverse degrees of severity. Even the patients with higher ABPI values presented a long-standing, clinically evident disease.

These results could indicate that plasma oxLDL levels may have a stronger impact in the early phase of the disease but not in the late phase, when PAD is already established.

Indeed, the work from Piarulli et al. demonstrated that plasma oxLDL levels were increased just among the longstanding diabetes patients. Their finding may be because steady and prolonged metabolic abnormalities are required to furnish a favorable environment for LDL to be oxidized. The pathophysiologic processes that occur due to the presence of oxLDL in the arterial wall microenvironment take place long thereafter. By the time the atherosclerotic disease becomes evident, the role played by oxLDL may be much less important.

There is also evidence that plasma oxLDL levels is increased in acute coronary syndrome ${ }^{34}$ and that these increased levels may have a relationship with the severity and the timing of that ischemic event. Plasma oxLDL levels are higher in the acute phase of the myocardial ischemia and decrease gradually over time. In our population, no patient presented acute ischemia or sudden worsening of the underlying critical ischemia. It is possible that in such stable cases, with no plaque-related acute events, great changes in oxLDL levels are not present.

A limitation of our work is its cross-sectional design. Although this kind of approach may enable important inferences, a prospective longitudinal study may reach more robust conclusions. However, to our knowledge, this is the first study assessing the correlation between ABPI and plasma oxLDL levels in patients with clinically evident PAD, and thus this study provides insight into the importance of this marker.

\section{CONCLUSION}

In conclusion, there is no correlation between ABPI and the plasma levels of autoantibodies against oxLDL in patients with clinically evident PAD. OxLDL is not a good predictor of the worsening or severity of peripheral atherosclerosis.

\section{REFERENCES}

1. Nasser M, Wolosker N, Uint L, Rosoky RA, Lobato M, Wajngarten $\mathrm{M}$, et al. Relationship between soluble thrombomodulin in patients with intermittent claudication and critical ischemia. Thromb Res. 2006;117:271-7.

2. Wolosker N, Rosoky RA, Nakano L, Basyches M, Puech-Leão P. Predictive value of the ankle-brachial index in the evaluation of intermittent claudication. Rev Hosp Clin Fac Med Sao Paulo. 2000;55:61-4

3. Wild SH, Byrne CD, Smith FB, Lee AJ, Fowkes FG. Low anklebrachial pressure index predicts increased risk of cardiovascular disease independent of the metabolic syndrome and conventional cardiovascular risk factors in the Edinburgh Artery Study. Diabetes Care. 2006;29:63742.

4. Ankle Brachial Index Collaboration, Fowkes FG, Murray GD, Butcher I, Heald CL, Lee RJ, Chambless LE, et al. Ankle brachial index combined with Framingham Risk Score to predict cardiovascular events and mortality: a meta-analysis. JAMA. 2008;300:197-208

5. Zaratin A, Gidlund M, Boschov P, Castilho L, de Faria EC. Antibodies against oxidized low-density lipoprotein in normolipidemic smokers. Am J Cardiol. 2002;90:651-3.

6. Zanati SG, Mouraria GG, Matsubara LS, Giannini M, Matsubara BB. Profile of cardiovascular risk factors and mortality in patients with symptomatic peripheral arterial disease. Clinics. 2009;64:323-6.
7. Crisostomo LM, Souza CA, Mendes CM, Coimbra SR, Favarato D, Luz PL. Vascular and metabolic response to statin in the mildly hypertensive hypercholesterolemic elderly. Clinics. 2008 Oct;63:589-94.

8. da Luz PL, Favarato D, Faria-Neto JR Jr, Lemos P, Chagas AC. High ratio of triglycerides to HDL-cholesterol predicts extensive coronary disease. Clinics. 2008;63:427-32.

9. Matheus AS, Cobas RA, Gomes MB. Dyslipidemias in type 1 diabetes: a current approach. Arq Bras Endocrinol Metabol. 2008;52:334-9.

10. Siqueira AF, Harima HA, Osiro K, Hirai AT, Gimeno SG, Ferreira SR; Japanese-Brazilian Diabetes Study Group. Lipid profile disturbances are highly prevalent in Japanese-Brazilians. Arq Bras Endocrinol Metabol. 2008;52:40-6.

11. Akalin A, Temiz G, Akcar N, Sensoy B. Short term effects of atorvastatin on endothelial functions and oxidized LDL levels in patients with type 2 diabetes. Endocr J. 2008;55:861-6.

12. Cominacini L, Rigoni A, Pasini AF, Garbin U, Davoli A, Campagnola $\mathrm{M}$, et al. The binding of oxidized low density lipoprotein (ox-LDL) to ox- LDL receptor-1 reduces the intracellular concentration of nitric oxide in endothelial cells through an increased production of superoxide. J Biol Chem. 2001;276:13750-5.

13. Boger RH, Sydow K, Borlak J, Thum T, Lenzen H, Schubert B, et al. LDL cholesterol upregulates synthesis of asymmetrical dimethylarginine in human endothelial cells: involvement of S-adenosylmethioninedependent methyltransferases. Circ Res. 2000;87:99-105. 
14. Scalera F, Borlak J, Beckmann B, Martens-Lobenhoffer J, Thum T, Täger M, et al. Endogenous nitric oxide synthesis inhibitor asymmetric dimethyl 1-arginine accelerates endothelial cell senescence. Arterioscler Thromb Vasc Biol. 2004;24:1816-22.

15. Galle J, Schneider R, Heinloth A, Wanner C, Galle PR, Conzelmann E, et al. Lp(a) and LDL induce apoptosis in human endothelial cells and in rabbit aorta: role of oxidative stress. Kidney Int. 1999;55:1450-61.

16. Heinloth A, Heermeier K, Raff U, Wanner C, Galle J. Stimulation of NADPH oxidase by oxidized low-density lipoprotein induces proliferation of human vascular endothelial cells. J Am Soc Nephrol. 2000;11:1819-25.

17. Galle J, Bengen J, Schollmeyer P, Wanner C. Impairment of endotheliumdependent dilation in rabbit renal arteries by oxidized lipoprotein(a) role of oxygen-derived radicals. Circulation. 1995;92:1582-9.

18. Galle J, Hansen-Hagge T, Wanner C, Seibold S. Impact of oxidized low density lipoprotein on vascular cells. Atherosclerosis. 2006;185:219-26.

19. Palinski W, Napoli C. The fetal origins of atherosclerosis: maternal hypercholesterolemia, and cholesterol-lowering or antioxidant treatment during pregnancy influence in utero programming and postnatal susceptibility to atherogenesis. FASEB J. 2002;16:1348-60

20. Nishi K, Itabe H, Uno M, Kitazato KT, Horiguchi H, Shinno K, et al. Oxidized LDL in carotid plaques and plasma associates with plaque instability. Arterioscler Thromb Vasc Biol. 2002;22:1649-54.

21. Crisby M, Nordin-Fredriksson G, Shah PK, Yano J, Zhu J, Nilsson J. Pravastatin treatment increases collagen content and decreases lipid content, inflammation, metalloproteinases, and cell death in human carotid plaques: Implications for plaque stabilization. Circulation. 2001;103:926-33.

22. Anselmi M, Garbin U, Agostoni P, Fusaro M, Pasini AF, Nava C, et al. Plasma levels of oxidized-low-density lipoproteins are higher in patients with unstable angina and correlated with angiographic coronary complex plaques. Atherosclerosis. 2006;185:114-20.

23. Liu ML, Ylitalo K, Salonen R, Salonen JT, Taskinen MR. Circulating oxidized low-density lipoprotein and its association with carotid intima-media thickness in asymptomatic members of familial combined hyperlipidemia families. Arterioscler Thromb Vasc Biol. 2004;24:14927.

24. Hulthe J, Fagerberg B. Circulating oxidized LDL is associated with subclinical atherosclerosis development and inflammatory cytokines (AIR Study). Arterioscler Thromb Vasc Biol. 2002;22:1162-7.
25. Matsumoto T, Takashima H, Ohira N, Tarutani Y, Yasuda Y, Yamane T, et al. Plasma level of oxidized low-density lipoprotein is an independent determinant of coronary macrovasomotor and microvasomotor responses induced by bradykinin. J Am Coll Cardiol. 2004;44:451-7.

26. Kugiyama K, Sugiyama S, Soejima H, Kawano H, Sakamoto T, Takazoe $\mathrm{K}$, et al. Increase in plasma levels of oxidized low-density lipoproteins in patients with coronary spastic angina. Atherosclerosis. 2001;154:463-7.

27. Tsimikas S, Brilakis ES, Miller ER, McConnell JP, Lennon RJ, Kornman KS, et al. Oxidized phospholipids, Lp(a) lipoprotein, and coronary artery disease. N Engl J Med. 2005;353:46-57.

28. Huang H, Mai W, Liu D, Hao Y, Tao J, Dong Y. The oxidation ratio of LDL: a predictor for coronary artery disease. Dis Markers. 2008;24:3419 .

29. Meisinger C, Baumert J, Khuseyinova N, Loewel H, Koenig W. Plasma oxidized low-density lipoprotein, a strong predictor for acute coronary heart disease events in apparently healthy, middle-aged men from the general population. Circulation. 2005;112:651-7.

30. Langlois MR, Rietzschel ER, De Buyzere ML, De Bacquer D, Bekaert $\mathrm{S}$, Blaton V, et al. Asklepios Investigators. Femoral plaques confound the association of circulating oxidized low-density lipoprotein with carotid atherosclerosis in a general population aged 35 to 55 years: the Asklepios Study. Arterioscler Thromb Vasc Biol. 2008;28:1563-8.

31. Tsimikas S, Kiechl S, Willeit J, Mayr M, Miller ER, Kronenberg F, et al. Oxidized phospholipids predict the presence and progression of carotid and femoral atherosclerosis and symptomatic cardiovascular disease: five-year prospective results from the Bruneck study. J Am Coll Cardiol. 2006;47:2219-28.

32. Piarulli F, Lapolla A, Sartore G, Rossetti C, Bax G, Noale M, et al. Autoantibodies against oxidized LDLs and atherosclerosis in type 2 diabetes. Diabetes Care. 2005;28:653-7.

33. Tsimikas S, Bergmark C, Beyer RW, Patel R, Pattison J, Miller E, et al. Temporal increases in plasma markers of oxidized low-density lipoprotein strongly reflect the presence of acute coronary syndromes. J Am Coll Cardiol. 2003;41:360-70.

34. Ehara S, Ueda M, Naruko T, Haze K, Itoh A, Otsuka M, et al. Elevated levels of oxidized low density lipoprotein show a positive relationship with the severity of acute coronary syndromes. Circulation. 2001;103:1955-60. 